\title{
Seasonality of Vegetation Types of South America Depicted by Moderate Resolution Imaging Spectroradiometer (MODIS) Time Series
}

\author{
Marcos Adami ${ }^{1}$, Sérgio Bernardes ${ }^{2}$, Egidio Arai ${ }^{1}$, Ramon M. Freitas ${ }^{3}$, Yosio E. \\ Shimabukuro ${ }^{1}$, Fernando D. B. Espírito-Santo ${ }^{4,5}$, Bernardo F. T. Rudorff ${ }^{6}$, Liana O. \\ Anderson $^{7}$
}

1 Remote Sensing Division, National Institute for Space Research. Av. dos Astronautas, 1758, São José dos Campos-SP, 12227-010, Brazil E-mail: adami@dsr.inpe.br (M.A.), egidio@dsr.inpe.br (E.A.), yosio@dsr.inpe.br (Y.S.)

2 Center for Geospatial Research, Department of Geography, University of Georgia, Athens, GA, USA. E-mail: sbernard@,uga.edu (S.B.)

3 R\&R Aerial Photography \& Imaging Science, Rua Fagundes Varela, 41 Curitiba, PR, Brazil. E-mail: aeroramon@gmail.com (R.F)

4 NASA Jet Propulsion Laboratory, California Institute of Technology, Pasadena, CA 91109, USA.

5 Lancaster Environment Centre (LEC), Lancaster University, Lancaster, UK LA1 4YQ. Email: f.delbon@gmail.com (F.E-S.)

6 Agrosatélite Geotecnologia Aplicada Ltda, Rodovia SC 401, Km 5, no 4850 - Loja E-23/30 - 88032-005 - Florianópolis - SC, Brazil. E-mail: bernardo@agrosatelite.com.br (B.R.)

7 Centro Nacional de Monitoramento e Alertas de Desastres Naturais - Cemaden, Estrada Dr. Altino Bondensan, 500 - São José dos Campos - SP, 12247-016, Brazil. E-mail: liana.anderson@,cemaden.gov.br (L.A.)

\begin{abstract}
The development, implementation and enforcement of policies involving the rational use of the land and the conservation of natural resources depend on an adequate characterization and understanding of the land cover, including its dynamics. This paper presents an approach for monitoring vegetation dynamics using high-quality time series of MODIS surface reflectance data by generatingfraction images using Linear Spectral Mixing Model (LSMM) over Soth America continent. The approach uses physically-based fraction images, which highlight target information and reduce data dimensionality. Further dimensionality was also reducedby using the vegetation fraction images as input to a Principal Component Analysis (PCA). The RGB composite of the first three PCA components, accounting for $\%$ of the dataset variability, showed good agreement with the main ecological regions of South America continent. The analysis of 21 temporal profiles of vegetation fraction values and precipitation data over South America showed the ability of vegetation fractions to represent phenological cycles over a variety of environments. Comparisons between vegetation fractions and precipitation data indicated the close relationship between water availability and leaf mass/chlorophyll content for several vegetation types. In addition, phenological changes and disturbance resulting from anthropogenic pressure were identified, particularly those associated with agricultural practices and forest removal. Therefore the proposed method supports the management of natural and non-natural ecosystems, and can
\end{abstract}


contribute to the understanding of key conservation issues in South America, including deforestation, disturbance and fire occurrence and management.

Keywords: vegetation dynamics; land cover; disturbance; phenology; MODIS; spectral mixing model; principal component analysis; time series.

\section{Introduction}

An adequate implementation of environmental management policies depends on an accurate characterization and understanding of the land cover. In particular, a proper representation of vegetation cover, including its dynamics, is essential for supporting the development, implementation and enforcement of policies involving the rational use of the land and the conservation of natural resources. The description of the Earth's surface has traditionally involved the identification and characterization of land use and land cover classes, with emphasis on their location and their spatial arrangement. Remote sensing has been a useful tool for conducting these tasks due to, among other factors, the synoptic view of large geographic regions and the lower associated costs, when compared to other acquisition data methods.

In spite of these advantages, analyses using remote sensing techniques have prioritized the understanding of space and have often used a single date or "snapshot" approach. Traditionally, less attention has been given to time and, in particular, to the high-frequency dynamics of several land cover types. Reasons include the limited availability of high-quality chronosequences of remotely-sensed images and the lack of adequate methodological approaches to process this type of data. The increasing availability of time series of satellite images, specifically provided by MODIS sensor, and the potential contribution of these images to environmental management and conservation emphasize the need for the development of specific approaches to properly deal with the unique nature and volume of these data [1].

Time series analyses address pressing issues involving the temporal characterization of land cover. These issues include the identification of types and patterns of changes in time and the incorporation of seasonality and phenological cycles of vegetation into analyses [2-3]. Many of these investigations have focused on regional and continental scales, incorporating products derived from one or more remote sensors onboard satellites orbiting the Earth. Examples of these applications include the Advanced Very High Resolution Radiometer (AVHRR, NOAA), Vegetation (SPOT) and Moderate Resolution Imaging Spectroradiometer (MODIS, Terra and Aqua) [2-10]. In particular, MODIS products have received significant attention from the scientific community, motivated by improvements in system design, data processing and product distribution. The geolocation accuracy of MODIS pixels, combined with the daily global coverage, moderate spatial resolution $(0.25$ to $1 \mathrm{~km})$, rapid availability of various products, and cost-free status (Lobell and Asner 2004)of the sensor support time- 
series analyses and the use of MODIS products for monitoring temporal changes of biophysical parameters of vegetation [11-12].

Vegetation indices (VI) are arguably the most used remote sensing products applied to regional and global studies of land use and land cover changes. Patterns of variations in VI values have been used to investigate physiological and structural seasonal changes in vegetation over large areas, including the identification of time of dormancy and the duration of vegetation cycles [2-8,10]. A large number of studies and operational applications have traditionally used the Normalized Difference Vegetation Index (NDVI), considering its simple formulation and its ability to describe biophysical properties of vegetation [13]. However, the biophysical limitations of NDVI when estimating structural vegetation parameters over dense canopy are well known in the remote sensing literature [13-16]. Then the images derived from spectral mixing models representing fractions of vegetation and other target types have been presented as an alternative to overcome some of VI limitations. Among other advantages, vegetation fractions offer a physically-based representation of vegetation conditions and are less prone to saturation when representing dense canopies, when compared to NDVI [17].

South America accounts for around 12\% of the Earth's land surface, being one of the most physically and biologically diverse regions on the planet. The large meridional extent of the continent, coupled with its topographic features and other physiographic characteristics, result in considerable climatic variability. The climate of South America ranges from equatorial at its northern fringe to icy-cold polar in the south. As a result, the continent is home to multiple biomes and ecoregions, including the largest remnant of tropical rainforest on the Earth, arid deserts and permanent ice caps [18]. South America also accounts for nearly a quarter of the world's potentially arable land, representing around $12 \%$ of the current cropland and $17 \%$ of all pasturelands [19]. The continent is under strong pressure for land occupation and resource utilization, resulting in several high-biodiversity areas currently being threatened.

In this context, this work has the objective to present a new toolset for environmental managers and decision makers by presenting and showing the applicability of a novel method to provide information for policy definition and environmental monitoring. The method supports the representation and analysis of land use and land cover dynamics, particularly the dynamics associated with high-frequency temporal variations in land cover classes and vegetation. The primary objective of this work was to verify the ability of time series of vegetation fractions derived from a linear spectral mixture model (LSMM) to represent and to describe seasonal changes in land cover and vegetation disturbance over highly-diverse terrestrial landscapes at a continental scale. Although the study considered the spatial representation of those fractions, we were particularly interested to know how the proposed method would perform when representing temporal variability, including seasonal and phenological changes of different land cover types and particularly relevant vegetation typologies. We showed the potential of the proposed approach over biomes of South America using approximately nine years of images acquired by the MODIS sensor onboard the Terra platform. 


\section{Material and Methods}

\subsection{Study area}

We demonstrate the usefulness of the proposed remotely-sensed based method to represent spatial and temporal vegetation variability in South America by identifying and sampling areas representative of a diverse conditions over the continent. Sampling took into account the MODIS dataset analyzed and previous field experiences of our research team and aimed to represent: (a) different vegetation types and densities; (b) seasonal pattern variability; and (c) different histories of disturbance and land use patterns. Samples include: areas along the interface between ecoregions; areas inside ecoregions; and agricultural areas (Figure 1).

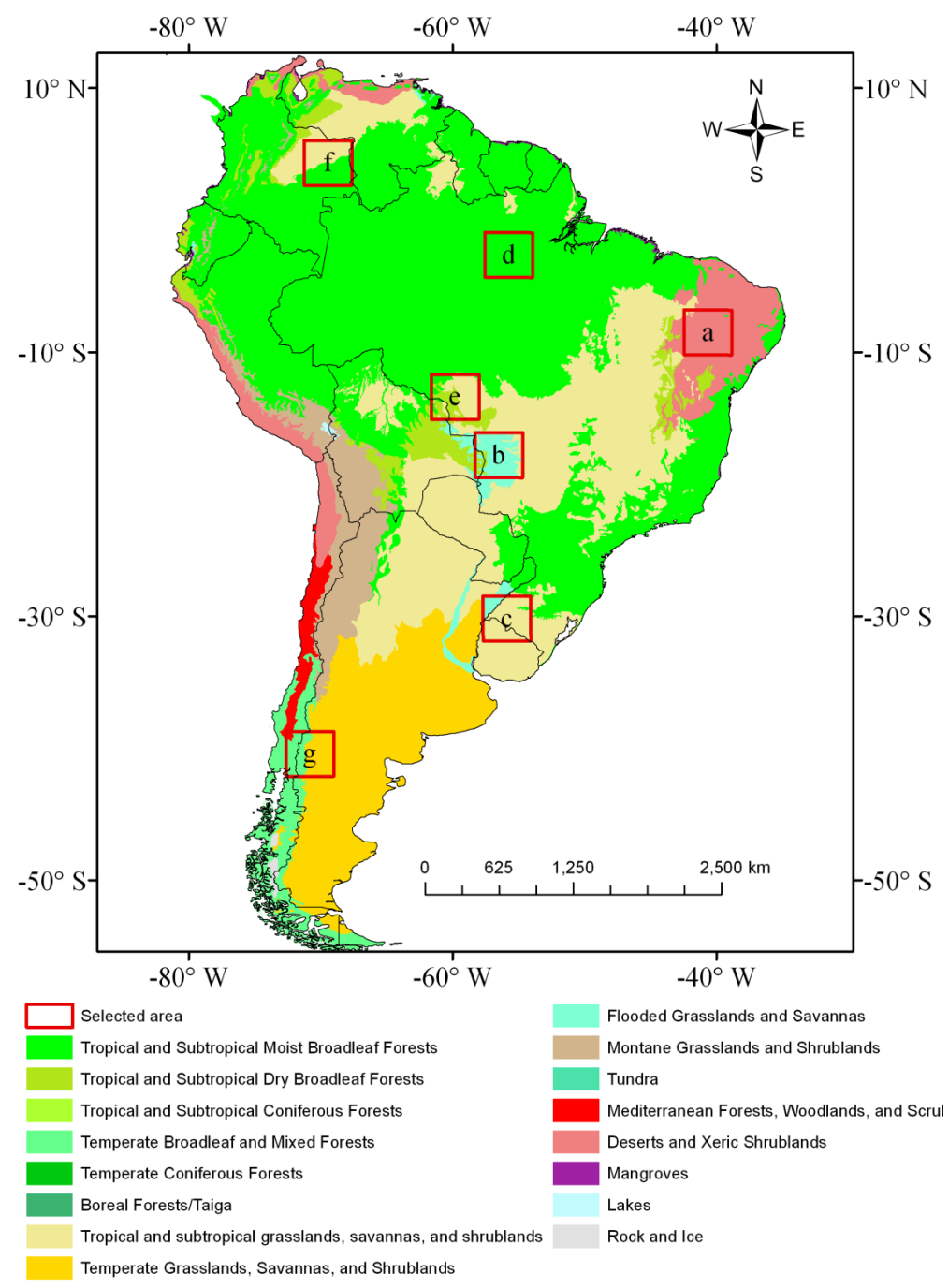

Figure 1. Distribution of South America Biomes [18] and selected areas: (a) Caatinga biome; (b) Pantanal biome; (c) transition region of physiognomies predominantly grassland (savanna-steppe, savanna and steppe grassy-woody); (d) Amazon biome; (e) transition forest region between the Amazon and Cerrado biomes; (f) transition region between the Amazon and Colombian llanos ecosystems (seasonal flooded savanna); and (g) temperate rain forest, Valdivian forests, temperate mixed forest, matorral and steppes. 


\subsection{Data}

We used approximately nine years of data acquired by the MODIS sensor onboard the Terra platform to extract vegetation seasonality patterns of selected points over South America. The MODIS surface reflectance bands from the Monthly $1 \mathrm{~km}$ product (MOD13A3) were used as input to a LSMM [20] to produce fraction images covering the entire continent. According to [21-22], reflectance bands from MOD13A3 have improved data quality due to the Constrained View Angle-Maximum Value Composite (CV-MVC) algorithm used in the generation of these products and to the screening of these data for clouds, aerosols and sensor artifacts (e.g., those resulting from large viewing angles and sensor noise). Although the CVMVC algorithm has been shown to be effective in selecting the highest-quality pixels available, we acknowledge that CV-MVC outputs may still be affected by residual contamination, particularly in the northern part of South America [23], but have not impacted our analyses as showed in the results section. See in the next section 2.3 for a more detailed discussion on the quality of the MOD13A3 dataset analyzed. We used all available bands from the MOD13A3 product: band 1 (620-670 nm), band 2 (841-876 nm), band 3 (459-479 $\mathrm{nm})$ and band $7(2105-2155 \mathrm{~nm})$. We processed 3,103 MODIS granules (29 tiles per month; 107 months) covering the entire surface of South America, corresponding to the tiles h09 to h14 and v07 to v14 of the MODIS reference grid. We also used the $1 \mathrm{~km}$ resolution yearly land cover classification product of MODIS (MCD12Q1) to support the identification of land cover classes and vegetation types for the sampled areas. MODIS data used in this work spanned from February 2000 to December 2008 time period. The work incorporated monthly precipitation data from the Tropical Rainfall Measuring Mission (TRMM), product 3B43 (V6). Precipitation data at $0.25 \times 0.25$ degree were produced by the TRMM Multi-Satellite Precipitation Analysis and incorporate precipitation estimates by TRMM and other satellites, global rain gauge data produced by NOAA's Climate Prediction Center and/or global rain gauge product created by the Global Precipitation Climatology Center (GPCC) [24]. We used the TRMM 3B43 (V6) monthly accumulated rainfall from February 2000 to December 2008 available at https://giovanni.sci.gsfc.nasa.gov/.

\subsection{Considerations about the quality of MOD13A3 over South America and implications to} studies of vegetation

The quality of products derived from MODIS can be affected by factors related to the image acquisition process, including the presence of clouds, cloud shadows and aerosols, and the geometry of image acquisition, among others. MODIS products bring improvements in data quality assurance and carry multiple metadata fields describing the quality of each pixel in the image. We used these metadata to investigate the spatial distribution of quality descriptors associated with images created by the MOD13A3 CV-MVC algorithm over South America. 
The work involved decoding and analyzing quality metadata for all MOD13A3 tiles used during the spectral unmixing procedure. Results of these analyses were then used to create quality summaries for the period 2000-2008, considering multiple quality flags of the MOD13A3 VI Quality Scientific Dataset. Quality flags considered included VI Quality (MODLAND, Figures 10A and 10B), Aerosol Quantity (Figure 10C), Adjacent Cloud Detected, Mixed Clouds, Possible Snow/Ice and Possible Shadow. The reader is referred to [21-22] for a description of those flags, including their encoding.
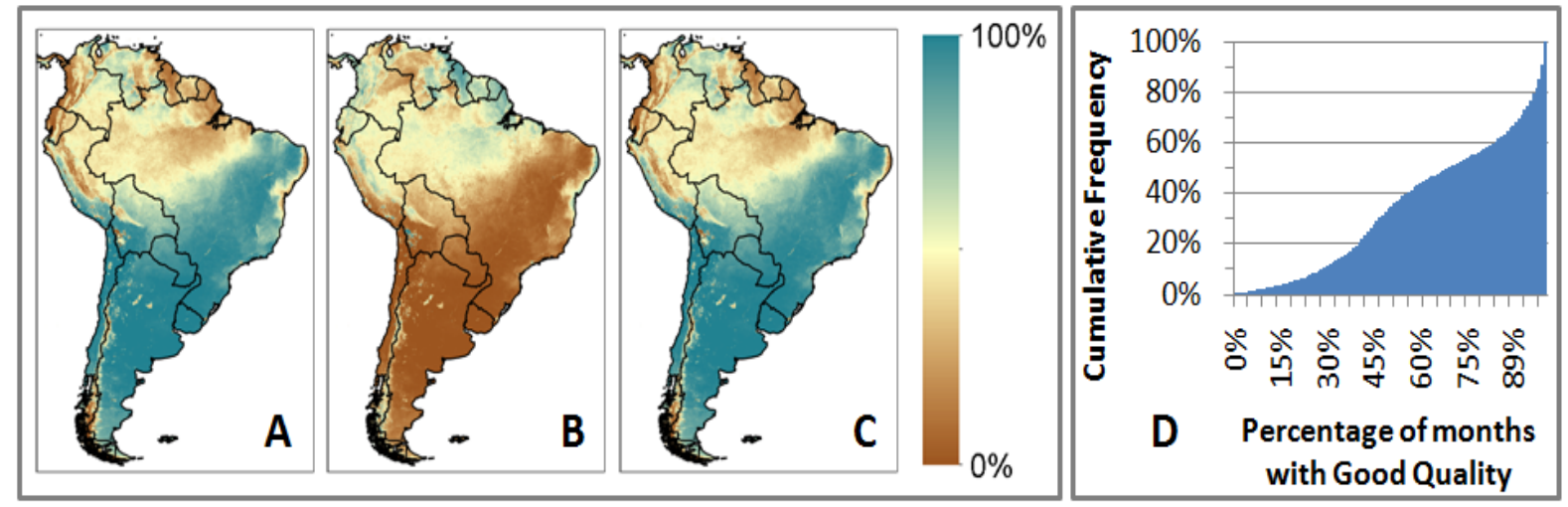

Figure 10. Summaries for the detailed Vegetation Index Quality Assessment Science Data Sets for MOD13A3, showing percentages of pixels acquired between 2000 and 2008 and including (A) pixels produced with good quality [MODLAND $=0$ ]; $(\mathbf{B})$ pixels produced, but other quality descriptors should be checked [MODLAND=1]; (C) pixels with low aerosol quantity [Aerosol Quantity=1] and (D) cumulative frequencies of pixel categories based on the percentage of Good Quality months during the 2000-2008 period.

Figure10A shows a summary for the MODLAND VI Quality metadata flag showing good quality data (MODLAND=0). For each pixel location, quality images were stacked and the number of good quality months for the period 2000-2008 was counted. The resulting total was then divided by the number of months analyzed by this work (107). The majority of pixel locations analyzed had more than $70 \%$ of their monthly pixels flagged as good quality (Figure 10D). The quality of the MOD13A3 composite bands over the continent is higher and approaches its maximum (green areas) over a large stretch from Patagonia to northeastern Brazil, including the northern part of Chile, southern Bolivia and the southern coast of Peru. Areas with reduced quality (brown and yellow areas) include the Pacific side of the southern tip of the continent, the northeastern coast of Brazil and a vast region in the northern part of the continent, including the Amazon region. MODIS metadata indicate that less than $34 \%$ of all pixel locations over the continent have $50 \%$ or less of their monthly pixels labeled as good quality (Figure 10D). We followed recommendations by [21-22] and inspected multiple quality assurance flags for pixel locations with reduced quality (MODLAND=1; Figure 10B). From all flags analyzed, the best match with the MODLAND $=0$ flag was observed for the low aerosol quantity flag (Aerosol Quantity=1, Figure 10C) of the VI Quality Assessment Science Dataset. 
Four of the areas we selected for detailed sampling (areas "a", "b", "c" and "g") are located in regions with high percentages of good quality pixels. Area "e" is situated in a transitional region, characterized by good quality occurring for approximately half of the months considered. Further interpretations for areas "d" and " $\mathrm{f}$ " should take into consideration the limited number of monthly composites labeled as having good quality. Reduced image quality can affect the analysis of time series and multiple methodologies have been proposed to deal with time-series reconstruction through gap filling and spike removal. However, no definitive method or procedural consensus exists involving those topics. We agree with [56] that the application of smoothing and filtering should be considered in a case-by-case basis. If judged necessary, these methodologies can be easily incorporated into our workflow as a preprocessing step. In particular, a spike removal approach could be used when identifying lowfrequency/low-amplitude variations in phenology, often characterized by gradual transitions in vegetation response. In other situations, including the current work, the nature of the analyses requires the ability to identify abrupt changes in data series.

\subsection{Methods}

The proposed method (Figure $\mathrm{xx}$ ) uses the surface reflectance data of MOD13A3 product from 2000 to 2008 time period, Linear Spectral Mixture Model (LSMM), Principal Component Analysis (PCA), precipitation data from TRMM 3B43, and Ecoregion and Land Cover maps. 


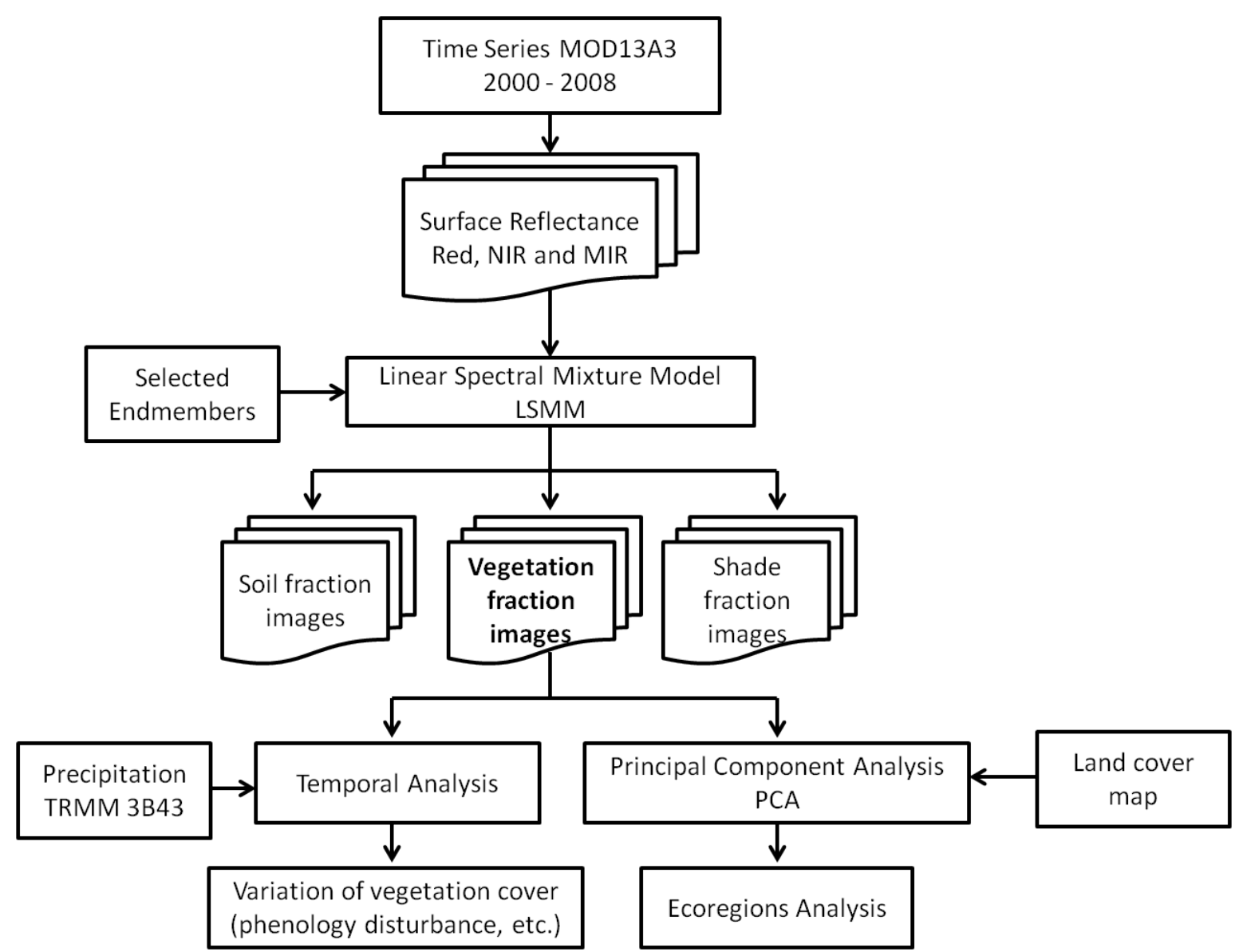

Figure Images derived from sensors with large instantaneous field of view (IFOV), such as MODIS, are prone to contain multiple scene objects inside a single pixel, that is known as the mixture problem. In these situations, pixel values do not represent a single object, but rather result from a mixture of the spectral contributions of multiple scene components. The problem of the mixed pixel has been addressed in numerous studies using linear mixing model (e.g., [20]Shimabukuro and Smith, 1991). These approaches model the reflectance of a pixel as a linear combination of endmember reflectances, weighted by the areal proportion of each endmember within the pixel.

Several approaches have been proposed to deal with this mixture problem and related solutions usually employ model inversion and the decomposition of pixels into their constituent components. Basically, two alternatives can be used to solve mixing equations: numerical methods or statistical methods. Different authors [25-26] have stated, however, that the algorithm employed to perform unmixing had little influence on the results. On the other hand, the linear approach has been demonstrated in numerous applications to be a useful technique for interpreting the variability in remote-sensing data and a powerful means for converting spectral information into data products with physical meaning such as abundance of materials on the ground surface [27]. Although different unmixing approaches have been described in the literature, when working with multispectral images, the most widely used method employs a single set of endmembers (typically three or four) on the whole image and uses a linear model to unmix the image pixel (constrained least squares method or inverse 
estimator) [28].When using these approaches, aspects such as the spectral response of these components (endmembers) and their fractional contribution to the final pixel value are considered [20,27].

We used a well-tested and widely-used LSMM approach for fraction image generation, following the works of [17,20,27,29-32]. The pixel decomposition method chosen is based on our previous results while processing MODIS images for the Amazon region [30] and included a least-square algorithm to decompose pixels into fraction values representing three components: green vegetation, soil and shade. The processing approach considered a time series of monthly MODIS reflectances spanning the period from February 2000 to December 2008, for the entire South American continent. Then fraction images representing the selected components were generated using a least-square mixing model following [20]. Below, we provide concepts regarding the linear unmixing of remotely-sensed spectra used by this investigation. Details on the implementation of the least-square mixing model are beyond the scope of this article and the reader is directed to [20] for further information. The linear unmixing approach used image endmembers to estimate the composition of every pixel [31], where a linear relation was assumed to represent the spectral mixture of components within the resolution element (pixel) of the remote sensing system [20]. The linear spectral mixture model used in this work can be formally presented as:

$$
d_{i}=\sum_{j=1}^{r} s_{i j} a_{j}+e_{i}
$$

where di is the observation for the ith band; aj is the fractional area or proportion covered by the jth component; sij is the ith component of the vector for the jth mixture component (the vector is often the reflectance of the mixture components, i.e., the component signatures) and; ei is the error term for the ith band. The matrix of endmember reflectances sij is typically assembled using reflectance field measurements [33] or by identifying samples of pure pixels in the scene for each cover type [32]. We selected the endmembers by identifying samples of pure pixels based on the analysis of MODIS dates corresponding to the dry and rainy seasons. Due to the high probability of existence of areas of bare soil during the dry season, an image acquired during this season (July 2005) was used to obtain reflectance values representing the pure soil component. Conversely, due to greater vegetative vigor, an image acquired during the rainy season (February 2002), was used to select the vegetation pure component. The shade pure component was collected over an area of clean water, due to the spectral similarity between these components.

Similar endemember selection was conducted by [34] that use a soybean plantation in the wet season as the vegetation endmember, an agricultural area in the dry season as the soil endmember and the shade endmember was from clean water bodies considering the spectral similarity between shade and water targets and the invariance of shade. The same set of pure components was used during the unmixing of the entire time series of MODIS reflectance 
images, producing fraction results that are comparable over time. The constrained unmixing solution for aj is determined by:

$$
\sum_{j=1}^{r} a_{j}=1 \quad \text { and } a_{j} \geq 0 \text { for all components. }
$$

The constraint equations above are strictly true only if the chosen components and their spectral signatures are an adequate representation of the mixture occurring within the pixel under analysis. Following [20] we determined the aj by using constrained least squares method. All four original MOD13A3 reflectance bands were considered during the unmixing procedure, aiming to generate fraction images representing green vegetation, soil and shade. This procedure reduces the data volume to be analyzed and also highlights the surface information. Vegetation fraction images enhance the cover status and conditions of vegetation, soil fraction images enhance the presence of bare soil, and shade fraction images enhance the dark components in the scene, including water bodies and burned areas. In this work, 107 sets of fraction images were generated, one set of fraction images for each month of the period analyzed. We inspected the quality of fraction images by analyzing its values in space and in time, but accuracy assessment for mixed pixels is challenging because (1) it is difficult to collect ground truth for each endmember considered at a scale compatible with the resolution of the remotely-sensed data and (2) traditional classification accuracy analysis measurement tools are not suitable for mixed pixel analysis [35]. Addressing the first challenge above, [36] found the following limitations when measuring proportions in the field: (1) uncertainties regarding the spatial boundaries of each pixel always exist; (2) noise resulting from atmospheric effects; and (3) internal variabity of each ground cover type.

Considering our interest in representing the temporal variation of vegetation, this work performs a analysis of the vegetation fraction time series. However, due to the complementary nature of fraction images, other components (particularly the soil fraction) were considered during the investigation. Moreover, we assumed that variations in vegetation fractions inside pixels occur primarily due to changes (increase or reduction) in ground cover by green photosynthesizing material, represented mainly by leaves. Several factors occurring at multiple spatial and temporal scales may be involved when changes are verified, including: leaf flushing, senescence and abscission, changes in species composition, vegetation removal, succession and cropping.

Following the generation of the fraction images, a Principal Component Analysis (PCA) was performed using the entire time series of vegetation fractions as input data. PCA has been widely used in remote sensing, meteorology and oceanography for temporal dataset analysis [9,37-41] and was selected due to its well-tested dimensionality reduction capabilities. The PCA algorithm involves a feature space transformation through linear combinations of variables and generation of uncorrelated principal components bands (PC). Among the resulting principal components, the first few bands concentrate most of the variance of the dataset, while the original total variance of the data is preserved. The contribution of each input band to a given PC is defined by corresponding eigenvectors and their signals, whether 
positive or negative, indicating direct and inverse relationships. The variance of these components is represented by eigenvalues. We used PCA as a data dimensionality reduction strategy, while aiming to preserve most of the variance and uniqueness of the original time series. To achieve that, the first three principal components resulting from PCA were used to represent the spatial and temporal variability of vegetation over South America. Random noise, clouds or cloud shadows are not depicted by the first PCA if they do not occur frequently, being represented by the remaining components [39]. Selecting three PCAs also allowed the generation of a PCA-based color composite by associating the first PCA component with the red channel $(\mathrm{PC} 1=\mathrm{Red})$, the second component with the green channel ( $\mathrm{PC} 2=$ Green) and the third component with the blue channel ( $\mathrm{PC} 3=\mathrm{Blue})$.

The time-series of fraction images was also analyzed by representing temporal variations of vegetation fractions for multiple vegetation/land cover types over the continent. For that, the MODIS land cover product (MCD12Q1) was used to support the selection of 21 nonrandom sampling points. Temporal profiles representing vegetation fraction for each month of the time series were generated by averaging fraction values inside a $3 \times 3$ pixel window positioned over a given sampling point. Temporal profiles of precipitation were used as ancillary data to investigate relationships between vegetation fractions and rainfall.

\section{Results and Discussion}

The results of two approaches used to investigate the spatiotemporal variation of land cover over South America are presented and discussed. Both methodological strategies make use of fraction images derived from a linear spectral mixture model and 3,103 monthly reflectance granules from MODIS-Terra. These approaches differ, however, in the way these fraction images were processed and presented. The following results include a PCA color composite derived from fraction images,temporal profiles of vegetation fractions coupled with rainfall data plotting, and how the information provided by this work can be used for environmental management and policy making.

\subsection{Representing seasonal variations in land cover using principal components from vegetation fractions}

The first three PCA components accounted for $92.9 \%$ of the total variance. All vegetation fraction images positively influenced the first principal component (PC1) which, as shown by the eigenvalues, mainly represents growing season months. For the second component (PC2), the highest positive influence was observed for the months of September, October and November, while maximum negative influence (inverse relationship) was observed for February, March and April. Relationships for the third component (PC3) were essentially similar to those observed for PC2, but a lag of three months was observed for this image. As a result, December, January and February had the highest positive influence over PC3, while May, June and July presented the highest negative influences. The variability presented by 
PC2 and PC3 highlights the seasonality of vegetation cycles over the South America continent (Figure 2A).

The color composite of the first three principal components generated using the time series of vegetation fraction images adequately represents the biomes present in South America. Results indicate boundaries and limits being particularly well defined when significant transitions in vegetation density occur (Figure 2B). It is noteworthy that the spatial distribution of surface features shown by this color composite presents high similarity to the more detailed ecoregion map proposed by [18]. Thus, despite the reduced number of spectral bands used and the relative coarse spatial resolution of MODIS, the use of vegetation fraction images and PCA allowed us to discriminate well the main ecoregions of South America. These results are in agreement with [9] who also suggested using PCA to define ecoregions.

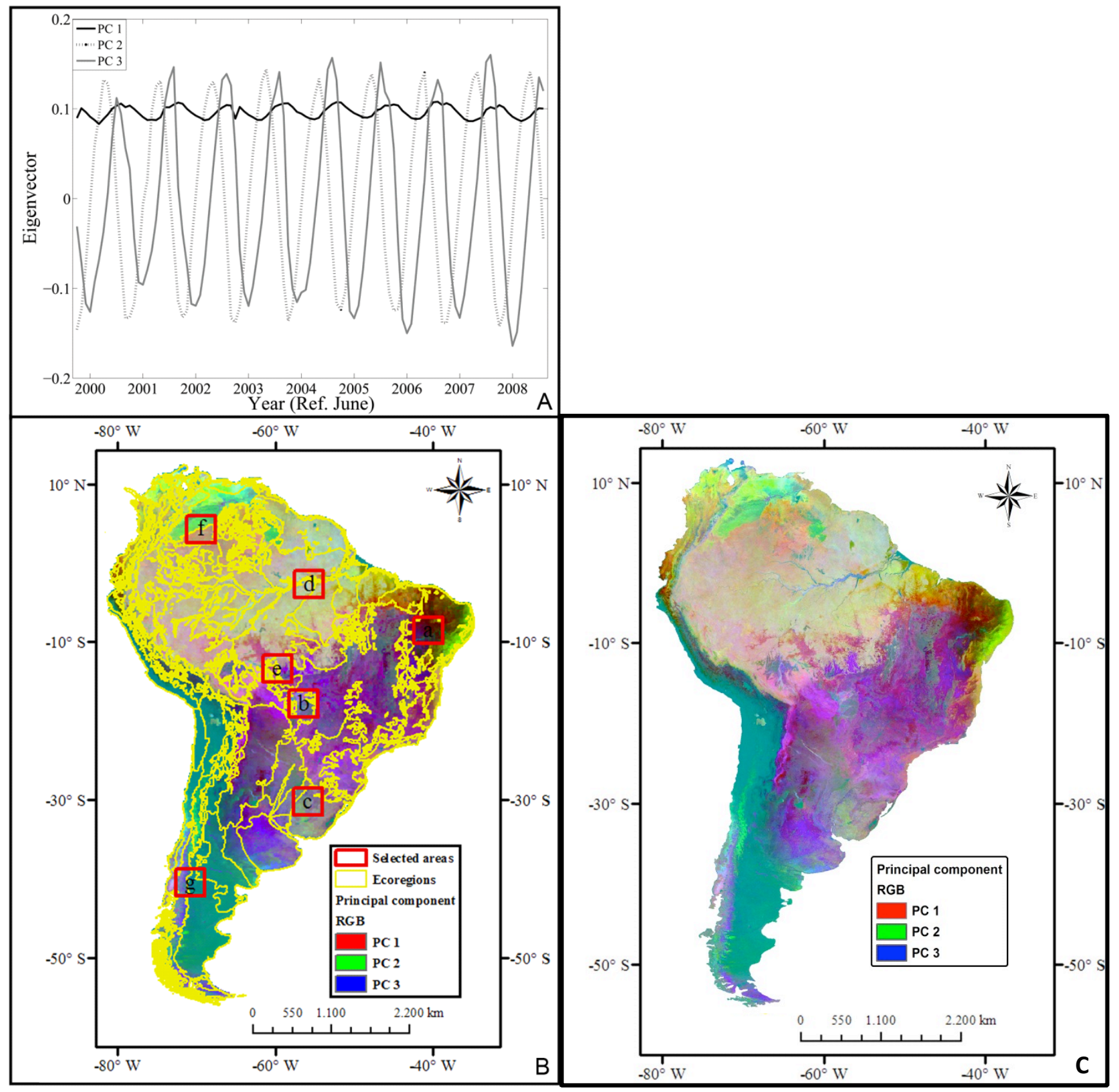


Figure 2. PCA analysis: (A) First three Eigenvectors, (B) Color composite of the first three principal components of vegetation fraction images and the vector boundary (in light yellow) of the major ecoregions in South America [18] and Red squares are areas selected for detailed sampling and further analyses, and (C) Color composite of the first three principal components of vegetation fraction images without the vector boundary.

Analyses based on the interpretation of the PCA color composite considered the strong contribution of $\mathrm{PC} 1$ and its representation of annual periodicity and amplitude of the vegetation fraction signal. The color composite resulting from PCA and presented by this work are based on the component-color combination: $\mathrm{PC} 1=\mathrm{Red}, \mathrm{PC} 2=\mathrm{Green}$ and $\mathrm{PC} 3=\mathrm{Blue}$. For these figures, red tones represent vegetation with periodical and well defined cycles [9]. In addition, vegetation types represented in red tend to exhibit higher amplitude of the vegetation fraction signal (sampling points 1, 6 and 14). Green tones (PC2) are associated with a time lag in seasonality when compared to $\mathrm{PC} 1$, being representative of vegetation types where small or large amplitudes in vegetation fraction could be observed (sampling points 4, 10, 17 and 19). The third component presents signals shifted in time when compared to PC2, adequately representing flooded areas and rivers (sampling point 12). In several instances, we observed an overlap between PC3 and PC1, showing the association between this third component and periodical signals (sampling points 8 and 15). Orange tones result from regions where contributions from PC1 and PC2 predominate, which are characteristic of areas with annual periodicity not well defined (sampling points 11, 13 and 18). These results are in agreement with [40] and [41] that investigated the relationship between PCA and vegetation cycles in different regions of Brazil.

\subsection{Representing seasonal variations in land cover using temporal profiles of vegetation} fraction images

This section characterizes temporal changes in vegetation cover, represented by chronosequences of vegetation fraction values for several sampling points over South America. Seven regions were selected for analysis and multiple points have been considered within those areas, aiming to represent their surface variability. The following text describes each of these regions.

The Caatinga (Figure 1a and Figure 3A) is a semi-arid area with native xerophilous species, characterized by well-defined wet and dry seasons, and lack of regularity in total annual rainfall [42]. We found three distinct regions within this area (Figure 3A). Region \#1 represents the hypo-xerophytic Caatinga, a vegetation type associated with higher water availability, when compared to other Caatinga physiognomies. As a result, this region presents characteristic denser vegetation, which is stratified in three layers. The time series of vegetation fraction values for this region present pronounced peaks with maximum values usually following maximum precipitation. Conversely, fractions of vegetation are usually lowest following periods of reduced precipitation. This pattern is strongly associated with physiological/physiognomical responses of vegetation to seasonal rainfall variations. Plants respond to the water availability by increasing leaf mass, which affects the region's spectral 
response and increasing the vegetation fraction values (Figure 3B). Region \#2 represents an area of transition between vegetation types (savanna and pluvial-nebular forest) and is characterized by higher water availability, caused by topographic gradients. The characteristics of the region contribute to the presence of evergreen species and dominance of a tree stratum. Figure $3 \mathrm{C}$ shows the temporal variation of vegetation fraction values for this region, indicating that despite the observable seasonal reductions in fraction values, the lowest fractions are still much higher than those observed for the savanna. These responses illustrate a characteristic of semi-deciduous vegetation during periods of lower rainfall (Figure 3C). Region \#3 refers to the hyper-xerophytic Caatinga which, due to low rainfall and long periods without precipitation ( 7 to 10 months without rain), is dominated by low vegetation and thorny shrubs. This vegetation is leafless during the dry season, while leaves grow after precipitation, during the rainy season [42]. On this site, the maximum fraction values are lower than those observed for Regions \#1 and \#2, indicating less exuberant vegetation even when water becomes available (Figure 3D). These results are in agreement with $[6,40,43]$ that investigated the relationship between a vegetation index and precipitation in Northeastern Brazil. These lower fractions of vegetation can be explained by the reduced amount of green photosynthetic material covering the ground and by higher soil fraction values (not shown). 


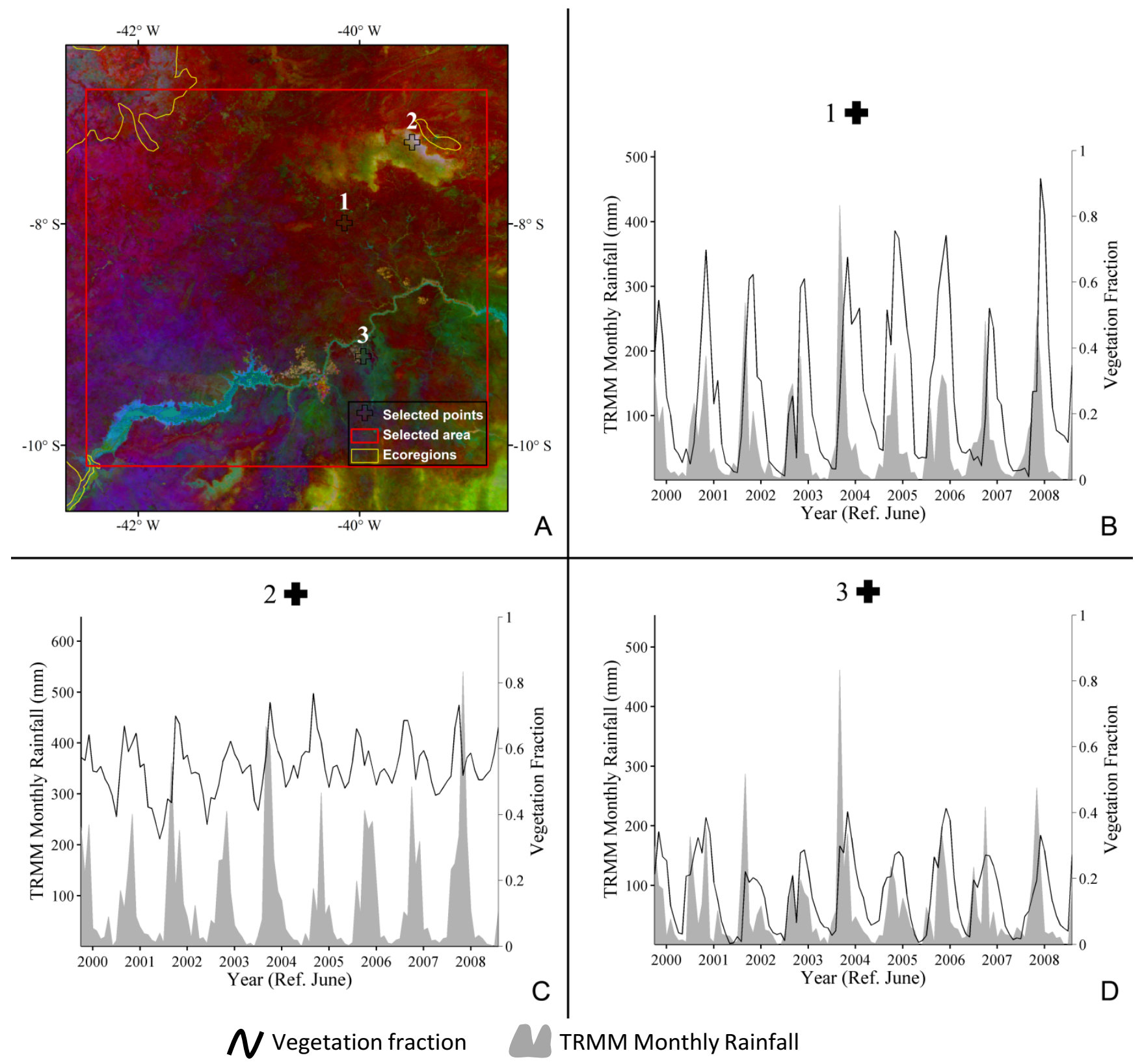

Figure 3. (A) Selected area "a", showing the Caatinga biome and sampled temporal profiles representing monthly vegetation fractions and precipitation from 2000 to 2008, and including: (B) Semi-arid area with native xerophilous species. (C) Transition between savanna and pluvial-nebular forest. (D) Semi-arid area with hyper-xerophytic Caatinga.

The Pantanal (Figure $1 \mathrm{~b}$ and Figure 4A) consists of a flooded savanna physiognomy, which extends across a relatively flat area with altitudes below $200 \mathrm{~m}$. The climate of this area is characterized by strong seasonality, with marked wet and dry seasons [44]. We analyzed multiple temporal patterns of vegetation fraction and identified three distinct regions in this area [45] (Figure 4A). Region \#4 is located in a permanently flooded alluvial area, with predominance of grassy shrub associations. The observed fraction values were particularly 
low, mainly due to the strong spectral contribution of water, an important scene component in this region [41] (Figure 4B). Region \#5 represents a transition area between grassland and savanna woodland. This sampling point represents a landscape dominated by grasslands, with the presence of water bodies interspersed with trees and shrubs, which are typical of a higher altitude Cerrado. During the dry season, the herbaceous vegetation and soil in areas surrounding the water bodies strongly influence the spectral response of this region. As a result, low values of vegetation fraction are observed (Figure 4C). Region \#6 represents areas of non-flooded, higher altitude savanna woodland with three strata and semi-deciduous forest species $[42,45]$. Oscillations in vegetation fraction for this area are characterized by high amplitude, particularly associated with variations in leaf mass content of the semi-deciduous vegetation (Figure 4D).

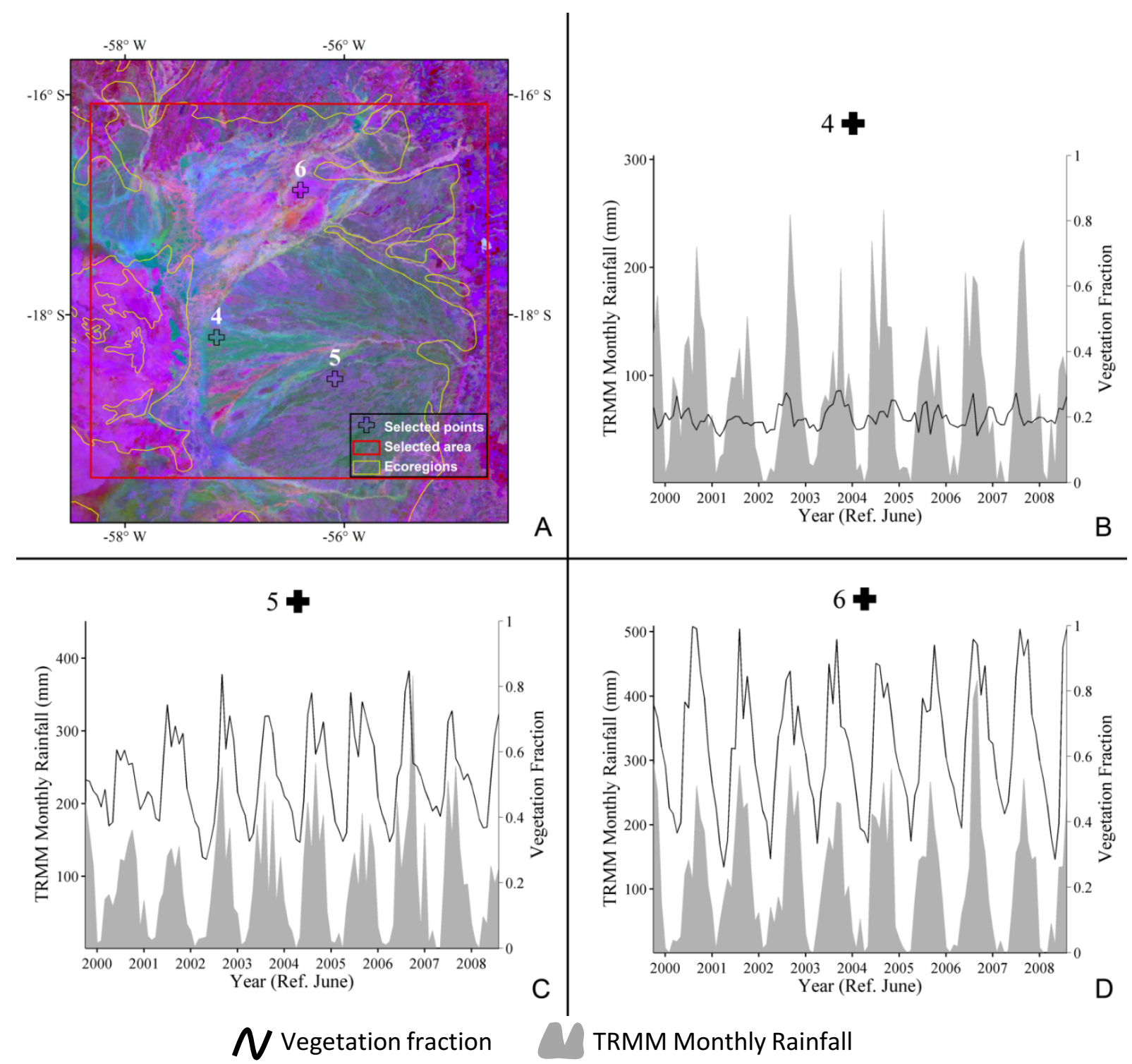

Figure 4. (A) Selected area "b", showing the Pantanal biome and sampled temporal profiles representing monthly vegetation fractions and precipitation from 2000 to 2008, and including: (B) Permanently flooded alluvial area, with predominance of grassy shrub associations. (C) Transition area between grassland and savanna woodland. (D) Savanna woodland. 
The Grassland area (Figure 1c and Figure 5A) comprises a transition of physiognomies dominated by grasses (e.g., savanna-steppe, savanna and steppe grassy-woody) in an area of gentle to wavy slope. The characteristic climate is subtropical humid with four well defined seasons $[42,46]$. This area concentrates intensive agro-forestry activities, with cattle and sheep ranching over natural pastures and vast areas of soybean and forest plantations, mainly Pine spp. and Eucalyptus spp. We describe temporal patterns of vegetation fractions for four regions of this area (Figure 5A). Region \#7 represents a forest plantation, associated with a recent change in land use. Reduced seasonality can be observed for this site, as demonstrated by the moderate to low amplitudes of vegetation fractions. The low fraction values observed correspond to winter times (Figure 5B). Region \#8 presents high amplitude and short phases of vegetation fraction values, characteristic of areas being cropped. A reduction in vegetation fraction maxima can be observed for the period 2001-2005, possibly associated with agricultural areas being left to rest, often also associated with the use of these areas for grazing. After 2005, the presence of annual summer crops is observed (Figure 5C). Region \#9 represents an area of intensive agriculture. Contrary to Region \#8, no resting period is observed for this area, although a reduction in vegetation fraction maxima can be observed for the years 2004-2005. Region \#9 also presents alternating high and low maxima, suggesting that this area is cultivated all year long with summer and winter crops (Figure 5D). Region \#10 represents an area of natural pasture, with temporal variations in vegetation fraction values being possibly associated with the local climate. Minimum fraction values possibly result from drier periods or occurrence of severe frosts (Figure 5E).

We selected the confluence of the Tapajós and Amazonas rivers to illustrate the Amazon region (Figure 1d and Figure 6A). The area is characterized by a tropical super-humid climate without a dry season, flat topography and the presence of vegetation physiognomies under fluvial influence [42]. Three regions (Figure 6A) were selected for temporal description of their vegetation fractions. Region \#11 represents a dense tropical forest with large diversity of species, typical of the area. Vegetation fractions values for this region range from 0.4 to 0.8 and present little to no periodical signal, resulting from high water availability and associated evergreenness of the forest [6]. The observed variations in vegetation fraction values may be explained by changes in canopy roughness, which may increase shadows and proportionally reduce the contribution of vegetation (Figure 6B). Region \#12 represents an Amazon River floodplain with the presence of seasonally flooded forest. Due to frequent flooding, this area is characterized by reduced vegetation diversity, when compared to Region \#11 [47]. The observed peaks in vegetation fraction values correspond to periods when the Amazon River is at its normal riverbed and the floodplain is not flooded. Conversely, when flooding occurs, water reaches these areas and reduction in vegetation fraction values can be noticed (Figure 6C). The sampling site for Region \#13 corresponds to a previously deforested area. This region is subject to strong human pressure being intensely occupied and used for agriculture [48-49]. Vegetation fraction values for this area present peaks with high values, as well as periodical signal, possibly associated with agricultural practices. The characteristic vegetation 
fraction variability resulting from the mixture of different land cover types can also be observed (Figure 6D). 

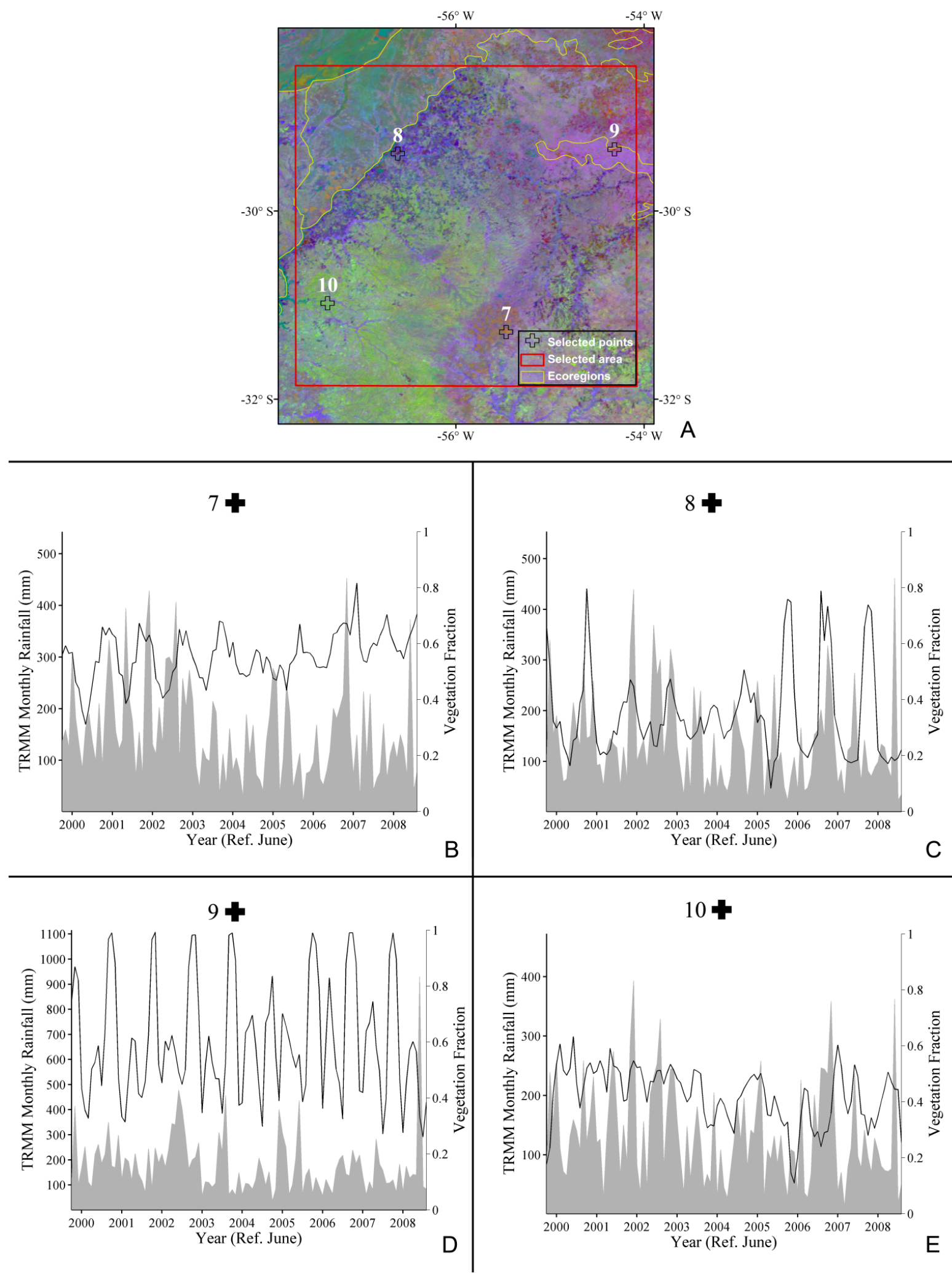

$N$ Vegetation fraction

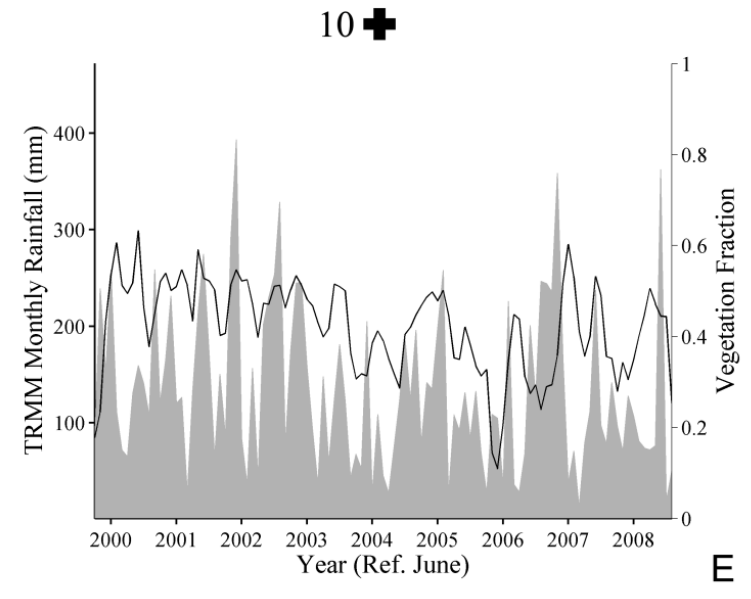

TRMM Monthly Rainfall

Figure 5. (A) Selected area "c", over Grassland area, and sampled temporal profiles representing monthly vegetation fractions and precipitation from 2000 to 2008, and including: (B) Forest plantations. (C) Agricultural areas. (D) Intensively cultivated areas. (E) Natural pasture. 

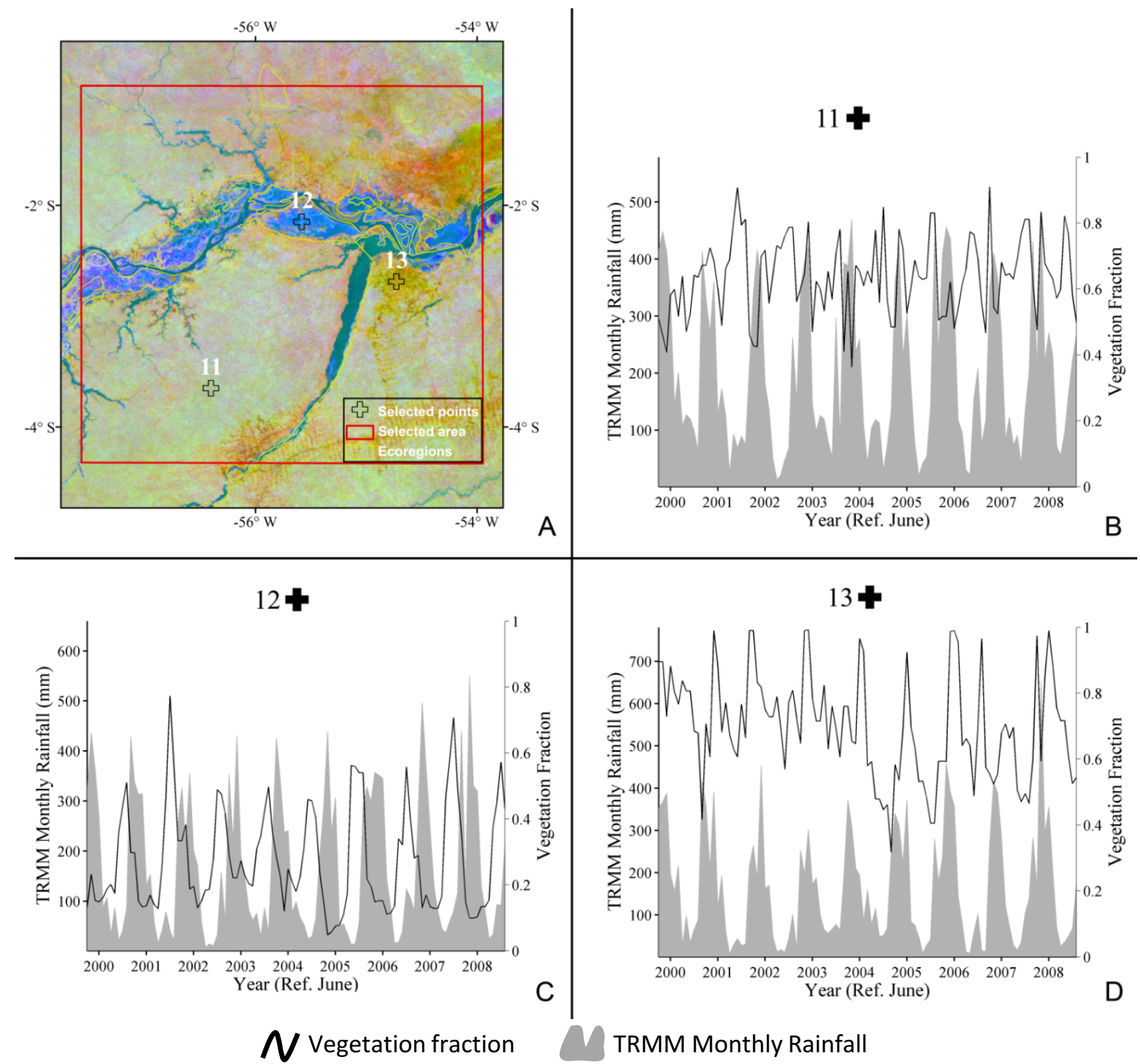

$N$ Vegetation fraction

Figure 6. (A) Selected area "d", over the Amazon region, and sampled temporal profiles representing monthly vegetation fractions and precipitation from 2000 to2008, and including: (B) Dense tropical forest. (C) Amazon river floodplain. (D) Deforested areas.

The transition area between the Amazon and the Cerrado (Figure 1e and Figure 7A) is characterized by a semi-humid climate with a dry season lasting four to five months. The area has flat topography and comprises the Brazilian agricultural frontier. It is therefore under particularly strong anthropogenic pressure. Activities found in this area include hightechnology intensive agriculture (mainly soybeans and corn), cattle ranching and logging [49]. Region \#14 lies in an agricultural area, which witnessed intensification in cultivation practices in recent years and the production of two crops annually [50]. The profile of vegetation fraction values is characteristic of areas being cropped, depicting high amplitude and short phases. Maximum vegetation fraction values are reached during the rainy season, when vegetation proportions are saturated due to total ground cover by crop canopies. At the peak of this season, soil and shade fractions reach zero (Figure 7B). Region \#15 is located in an 
area of Cerrado (savanna woodland and park) in the Xingu Indian reserve. Due to an increased presence of a graminoid stratum, spectral responses for this region are more influenced by the soil, resulting in lower vegetation fraction values. The periodicity of the vegetation signal for this region is particularly well defined, as fraction values reflect the occurrence of a dry season (Figure 7C). Similar results were obtained by [6,40] while studying areas of Cerrado. Region \#16 represents an area of forest cleared in 2004, as indicated by the sudden drop in vegetation fraction values. These values also indicate that the area was being used for agriculture after the second year following clearing (figure 7D).

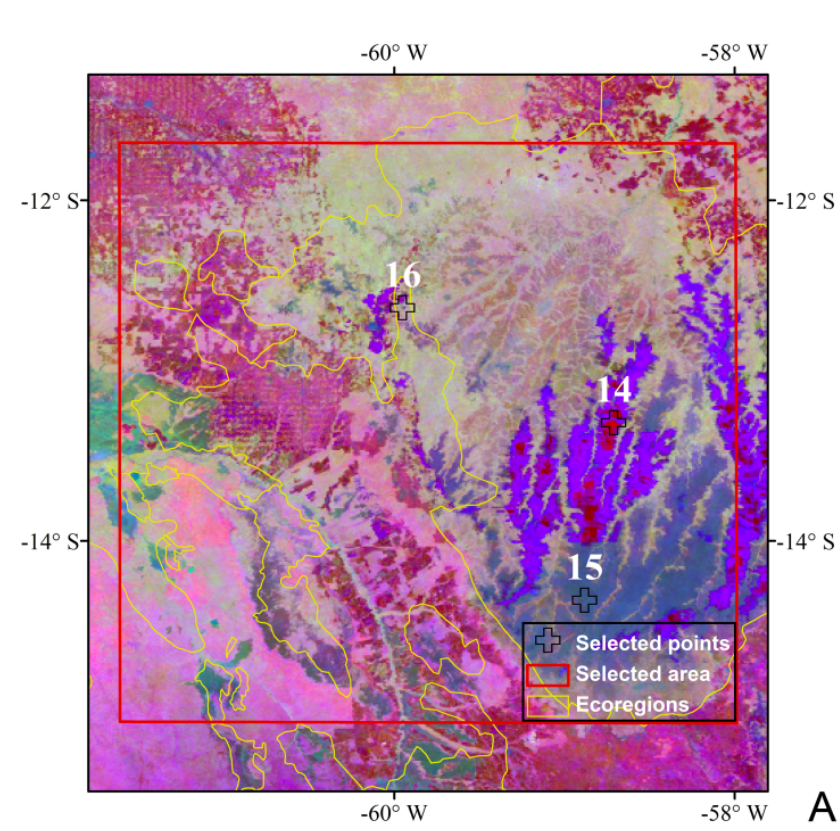

\section{4}
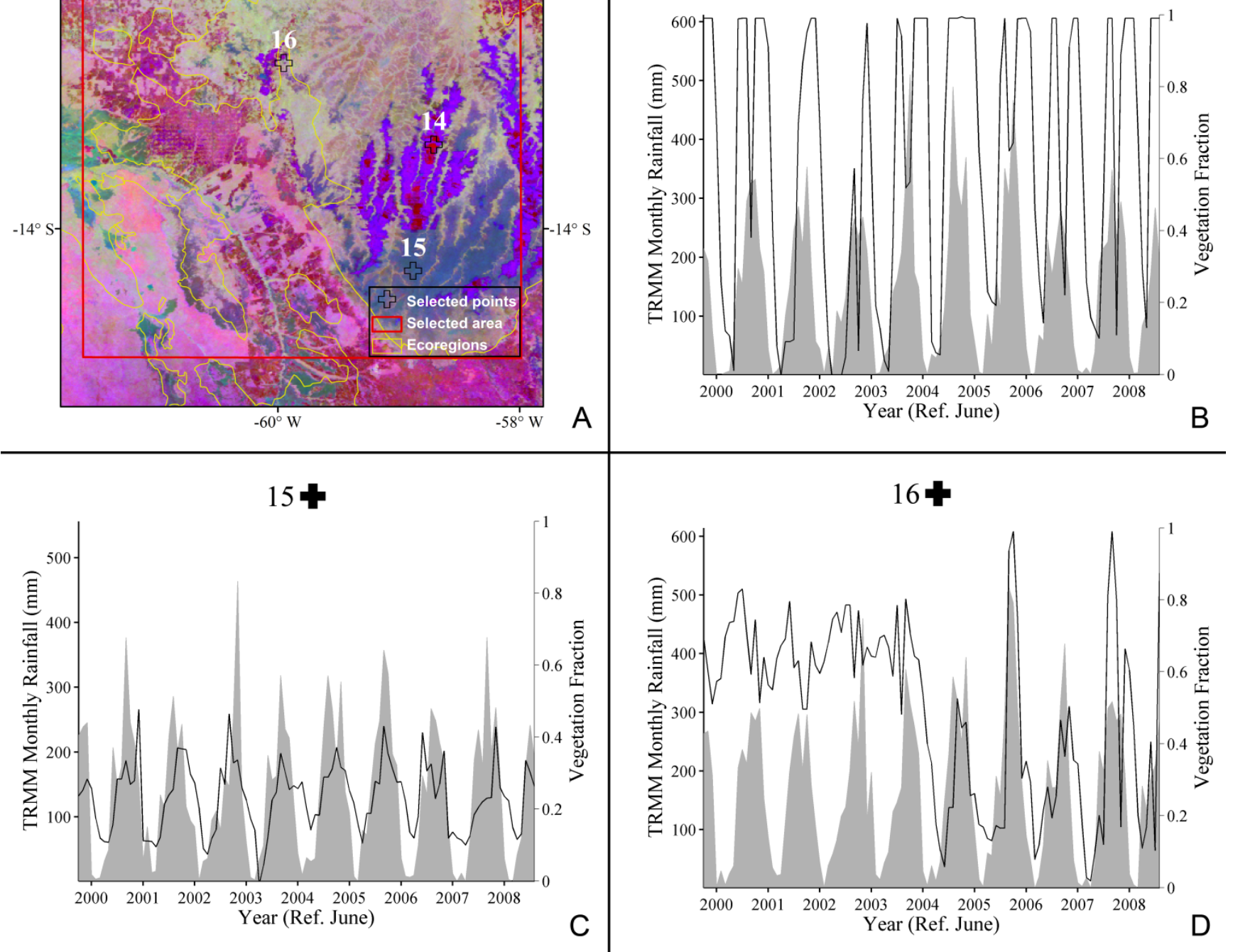

164

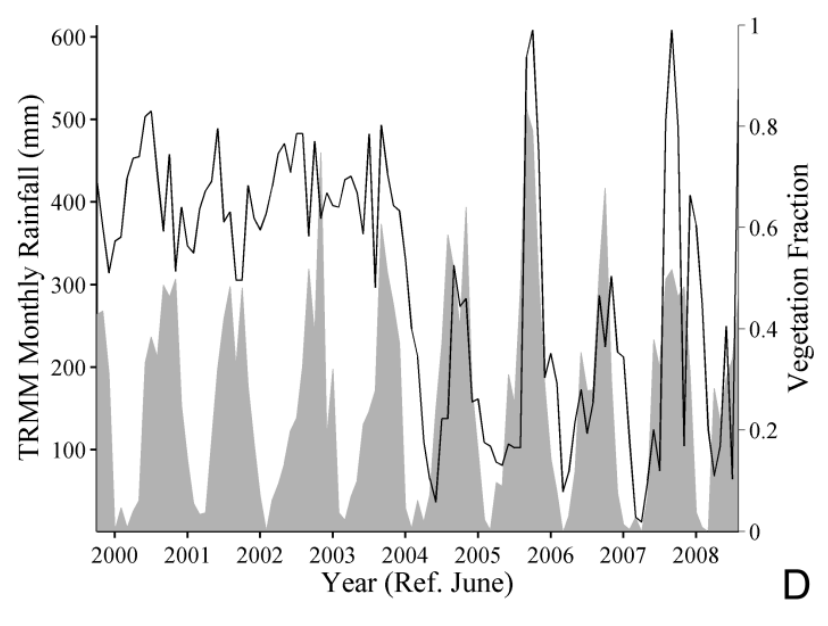

$\mathcal{V}$ Vegetation fraction

TRMM Monthly Rainfall

Figure 7. (A) Selected area "e", over transition area between the Amazon and Cerrado, and sampled temporal profiles representing monthly vegetation fractions and precipitation from 2000 to2008, and including: (B) Agricultural areas. (C) Cerrado in Xingu Indian reserve. (D) Deforested areas. 
The transition area between the Amazon and the Colombian llanos (seasonal flooded savanna) (Figure 1f and Figure 8A) is marked by a sudden break in landscape continuity (enclave) between the high Amazonian plains and the lower altitude floodplain, where the llano plains are. The area presents high monthly average temperatures and a seasonal climate, with the occurrence of wet and dry seasons. Region \#17 is located in an area of savanna with palms, ecologically characterized by water log and saturated soils during flooding periods [51]. The profile of vegetation fraction values illustrates the marked seasonality of this region, with peaks coinciding with periods of higher precipitation (Figure 8B). Region \#18 is located in an area of dense tropical rain forest (Figure $8 \mathrm{C}$ ), presenting variations in vegetation fractions similar to Region \#12, with no observable seasonal pattern.

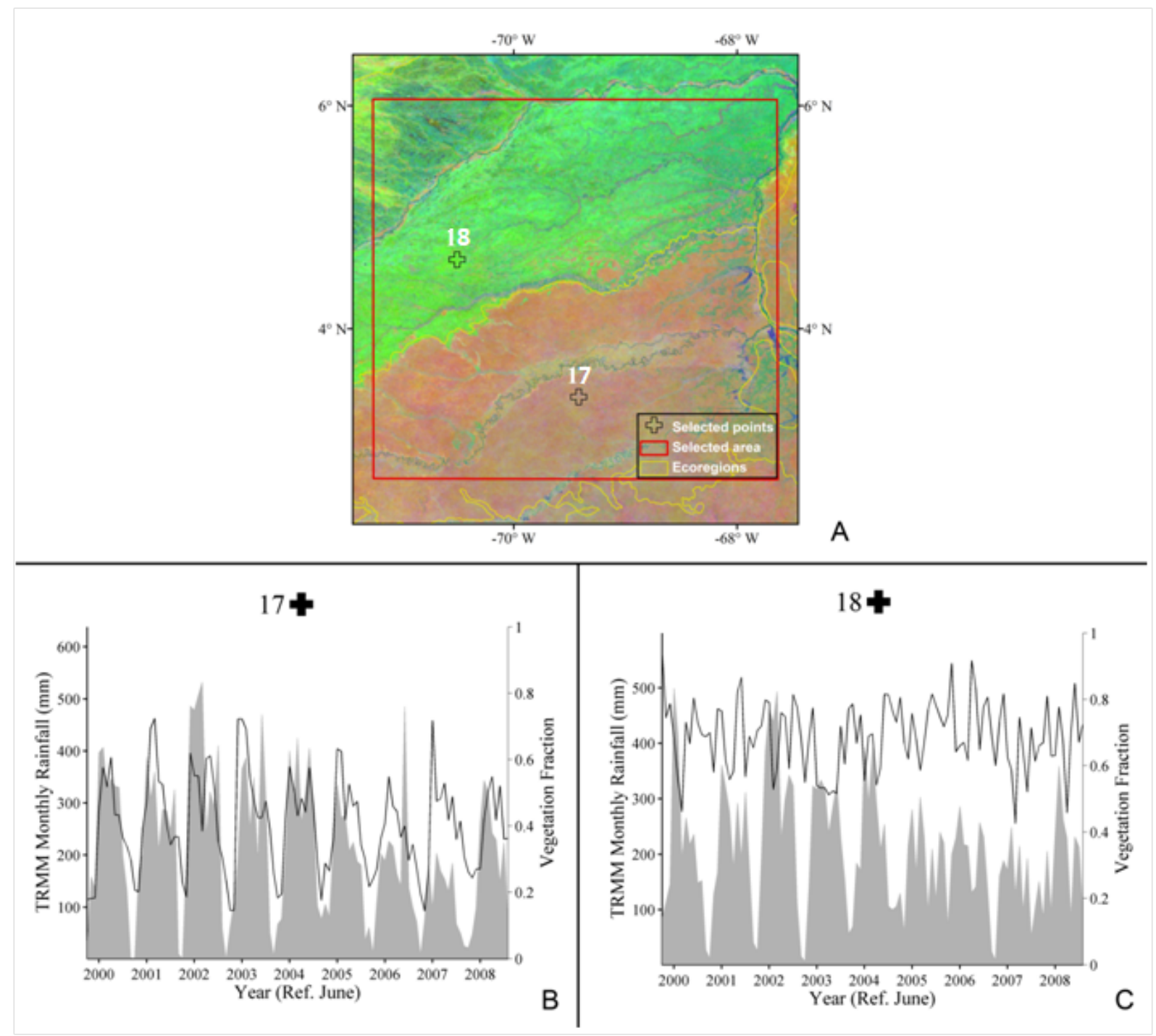

$\Upsilon$ Vegetation fraction

TRMM Monthly Rainfall

PRECISA TROCAR A POSIÇÃO DOS PONTOS NA FIGURA (17 E 18)

Figure 8. (A) Selected area " $\mathrm{f}$ ", over area of transition between the Amazon and the Colombian llanos, and sampled temporal profiles representing monthly 
vegetation fractions and precipitation from 2000 to2008, and including: (B) Colombian llanos. (C) Dense tropical rain forest.

The region representing the Valdivian forests, the temperate mixed forest and the steppes of South America (Figure 1g and Figure 9A) is marked by a large diversity of environments and climates. On the east side of the region, factors such as continentality, topographic effect exerted by the Andes and Austral influence favor low temperatures and reduced precipitation, preventing the survival of trees and contributing to the presence of steppes. Along the coastal region, at higher latitudes, still under coastal influence, the climate is milder and stable with mild/wet winters and dry summers, characteristic of areas of Mediterranean vegetation. Areas with cold temperatures and high precipitation present forest types typical of temperate climates [52]. Region \#19 represents the grassy steppes of Patagonia with woody xeric characteristics. The temporal variation of the vegetation fraction for this site indicates the seasonal pattern of vegetation, which is strongly influenced by the arid and cold climate [53]. The low values displayed by the vegetation fraction indicate low density of the vegetation component and the contribution of other scene elements, particularly of soil (Figure 9B). Region \#20 is located in a formation of Valdivian forests (relict of past geographical and climatic conditions), characterized by the presence of evergreen broadleaf hydrophilic species [54]. This vegetation type is under high human pressure and is considered one of the most threatened ecosystems in the world [55]. The temporal profile of vegetation fraction values for this region reflects a vegetation type with well-defined seasonality. Maximum vegetation fraction values are reached just before summer, while minimum values are observed before winter time (Figure 9C). Region \#21 represents a temperate mixed forest with the presence of Araucaria spp. This area has a rainy temperate oceanic climate, with dry periods extending for one to two months [54]. Due to its high biodiversity and to the presence of endemic species, the conservation of this region, currently threatened by the logging and agro-forestry industry, is very important [55]. Temporal variations in vegetation fraction values for this region exhibit a characteristic seasonal profile (Figure 9D). 


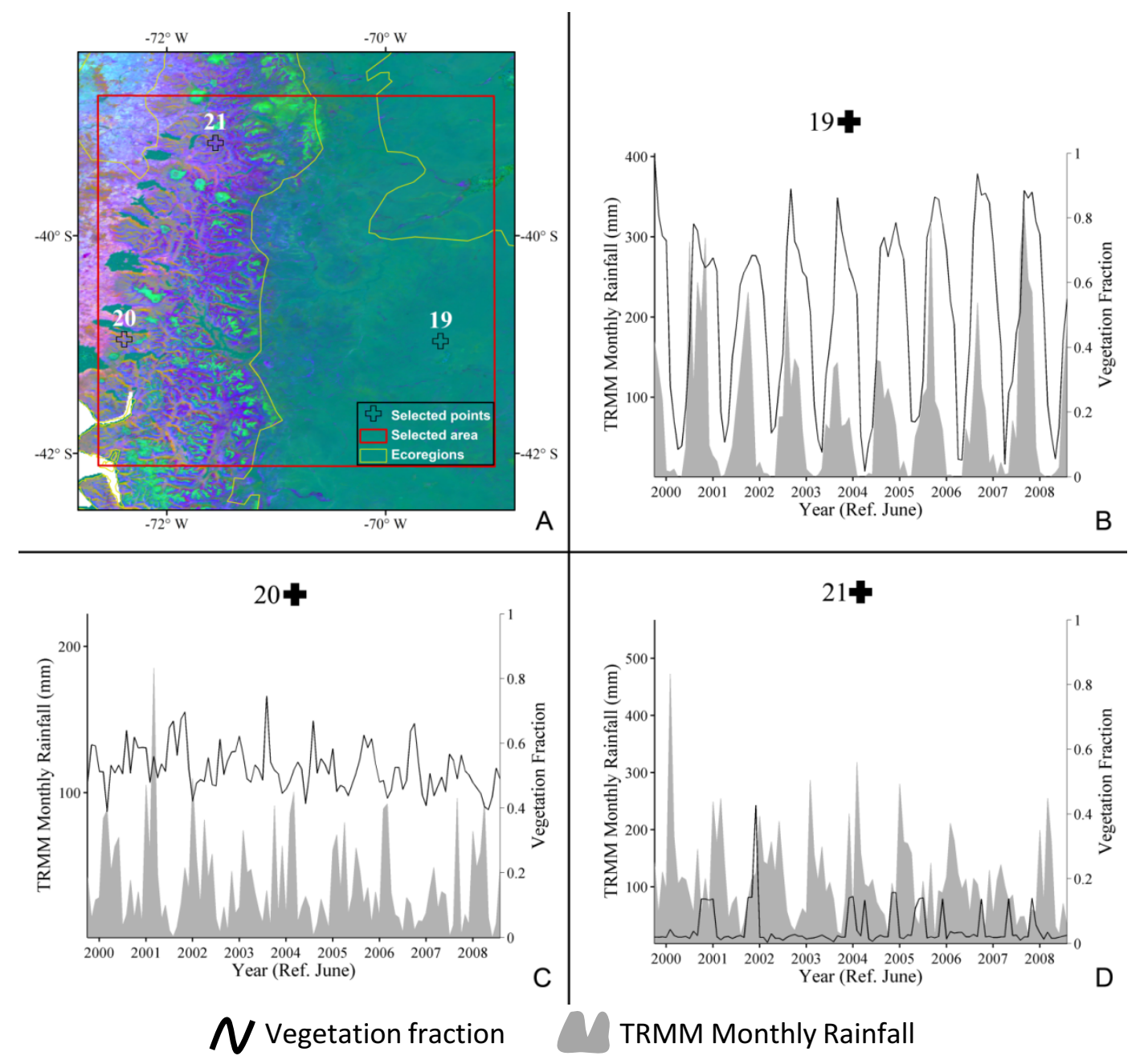

Figure 9. (A) Selected area "g", over Valdivian forests, temperate mixed forest and steppes, and sampled temporal profiles representing monthly vegetation fractions and precipitation from 2000 to2008, and including: (B) Grassy steppes of Patagonia. (C) Valdivian forest formation. (D) Temperate mixed forest. 


\section{3 information for environmental management and policy making}

An adequate implementation of environmental management policies and practices depends on the accurate characterization and understanding of the land cover. Traditional land cover characterization strategies based on single-date and hard-classification methods often oversimplify the landscape, thus failing to address the complexity of important ecosystems. The methodology proposed by this investigation overcomes these limitations by integrating space and time, more accurately representing and synthetizing the fuzzy nature of environmental data. Furthermore, environmental management and decision making are highly dependent on the ability to measure, understand and respond to changes on ecosystem descriptors. The proposed physically-based method using time series of vegetation fractions contributes to the toolset available to managers and decision makers, supporting analyses and facilitating the assimilation of results.

In South America, this enhanced characterization capability can lead to a better understanding and management of the complexity associated with areas of savanna. These areas, characterized by a number of endemic species and the co-existence of grasses and trees in a gradient of proportions, have important ecological and societal roles, being often associated with disputes involving conservation and the use of land and natural resources. Laws and policies regulating the use of savanna areas frequently refer to specific facies of this vegetation type. For instance, the state of São Paulo, in Brazil, uses a tree-density based fourclass stratification of the state savannas to regulate licensing and enforcement (Sao Paulo state law 13,550). This stratification is supported by the methodology proposed by this

investigation. In this context, vegetation fractions can be used for vegetation density identification and principal components from these fractions can be employed to represent seasonality characteristic of savannas. Besides, the proposed approach generates continuous fields, more naturally representing the natural gradients associated with these areas. If needed, thresholds representing the limits of a particular class could be used to generate hard classifications.

Although savanna ecosystems depend on fire for organic matter mineralization and nutrient recycling, uncontrolled fires can have devastating effects on these systems and profoundly affect their biota. Decisions associated with vegetation fire management, including the definition of areas to burn and time elapsed between prescribed burning events, should incorporate the knowledge of the amount of dead material available to be consumed by fire. Temporal profiles of vegetation fractions and the monitoring of changes in these fractions can be used to support inferences regarding biomass accumulation, including the incorporation of these variables into fire models in support to decision making. Fire events and their timing can also be identified, considering the associated reduction in vegetation fraction values that can be observed in our results.

Deforestation is a major concern in many parts of South America, being a critical issue in the Amazon region. Forest removal in the Amazon, usually associated with cattle ranching, agriculture and timber industry, has been linked to local, regional and global environmental 
impacts. Recent international and domestic pressures have led South American countries to set and enforce laws regulating forest removal. The proposed strategies for deforestation regulation rely on monitoring vegetation status, either by identifying total vegetation removal or, more recently, by recognizing signs of forest degradation. It has been demonstrated that clear cut of forested areas can be easily identified in time series of vegetation fractions, as cut events result in abrupt reductions in fraction values. Forest degradation, however, has a more subtle signal than total forest removal, resulting in greater identification and quantification challenges. Difficulties in investigating forest degradation are particularly relevant when the methods employed do not consider the dynamics of the degradation process and rely solely on single-date analysis. Our results show that successive temporal reductions in vegetation fraction values for a given region can be used to flag areas where further assessment of potential forest degradation would be appropriate.

The understanding of the aforementioned vegetation disturbance process and results is essential to support conservation practices and the recovering of these areas. Despite the incorporation of disturbance into legislation involving the management of successional stages of vegetation, in practice, the implementation and enforcement of the resulting policies have proven to be difficult. In particular, methods for the classification of successional stages based on single-date analyses fail to capture the complexity and dynamics of the affected areas. Because the characteristics of the successional process result from multiple factors, including the original natural vegetation, land uses and practices, as well as time, it is fundamental to understand the history of areas recovering from disturbance. Aspects such as the nature and intensity of the disturbance, land uses, practices and time elapsed after disturbance can be jointly analyzed to derive a more complete identification of the successional process, supporting comparative analyses between successional areas. For instance, the legislation protecting areas of savanna in Brazil is based on a three-class classification system for savanna regrowth (i.e., initial, intermediary and advanced). These classes can be better identified using temporal profiles of vegetation descriptors as presented in this work.

Initiatives associated with carbon market and credit have considered the potential of allocating large areas in South America for carbon offset, including forest preservation, afforestation and reforestation. Such markets require the monitoring and quantification of carbon stocks and can benefit from remote-sensing based strategies to verify compliance with the legislation and estimate of carbon stored. Series of vegetation fractions can be used to identify deviations from predefined allocation, including total vegetation removal, selective logging and forest degradation, as well as the non-implementation of afforestation/reforestation.

\section{Conclusions}

The increasing availability of high quality time-series of remotely sensed images emphasizes the need for methodologies able to process and support the analysis of the resulting high data volume. Although vegetation indices are often used when analyzing image 
chronosequences, reduction in sensitivity under high biomass and the contribution of the soil background and atmosphere limit the applicability of these indices over certain areas. We proposed a method to analyze temporal variations in land cover (particularly vegetated areas), based on the generation of fraction images, resulting from a linear spectral mixture model considering three components: vegetation, soil and shade. Vegetation fraction images represent the proportional contribution of vegetation to the total energy received by a remote sensor having, therefore, close relationship with biophysical characteristics of the vegetation cover. Results from a Principal Component Analysis of vegetation fraction images showed good correspondence with the main ecological regions of South America, highlighting seasonality and the spatial-temporal variability of vegetation. Moreover, the generated timeseries of vegetation fraction were used to present temporal profiles of 21 sampling points distributed over important vegetation cover types in South America. The analysis, considering also the corresponding precipitation dataset, showed the ability of the vegetation fraction profiles to represent vegetation phenological cycles over a variety of environments. The regions analyzed demonstrated high variability in temporal responses, exemplified by the strong seasonality in vegetation fraction observed for savannas and the less evident seasonal signal of tropical forests. Besides analyzing cycles of natural vegetation, we demonstrated the utility of the methodology to capture phenological and disturbance-related changes over areas under anthropogenic pressure, particularly when associated with agricultural practices and forest removal. Changes in ground cover and soil exposure during crop development can be adequately represented using time series of vegetation fractions. Moreover, comparisons between vegetation fractions and rainfall data indicated the close relationship between water availability and leaf mass/chlorophyll content for several vegetation types. This relationship was particularly strong for areas with marked seasonality and well-defined dry season.

\section{Author contributions}

Y.E.S designed the study, M.A., E.A., R.M.F. conducted the analysis, M.A., R.M.F., S.B. and, Y.E.S wrote the manuscript. S.B., F. E-S., B.F.T.R. and L.O.A. advised on the data used in the analysis. All authors contributed to the manuscript preparation.

\section{Acknowledgments}

The contribution of Y.E.S. was supported by a grant from the Fundação de Amparo à Pesquisa do Estado de São Paulo (FAPESP). S.B. and F. E-S. were supported by a NASA Earth and Space Science Fellowship (NESSF). F. E-S. was also supported by a JPL-CalTech Post-Doctoral Fellowship and Newton Fund (The UK Academies/FAPESP Proc. $\mathrm{N}^{\circ}$ : 2015/50392-8 - Fellowship and Research Mobility). The authors gratefully thank the Coordenação de Aperfeiçoamento de Pessoal de Nível Superior (CAPES), Conselho Nacional de Desenvolvimento Científico e Tecnológico (CNPq) and Large Scale BiosphereAtmosphere Experiment in Amazonia (LBA). 


\section{Data accessibility}

The MODIS images and all dataset used in this research are publically available from the NASA data archive. All relevant data are within the paper and available for download.

\section{References}

1. McCloy, K.R. Development and Evaluation of Phenological Change Indices Derived from Time Series of Image Data. Remote Sensing 2010, 2, 2442-2473.

2. Lunetta, R.S.; Knight, J.F.; Ediriwickrema, J.; Lyon, J.G.; Worthy, L.D. Land-cover change detection using multi-temporal MODIS NDVI data. Remote Sensing of Environment 2006, 105, 142-154.

3. Wardlow, B.D.; Kastens, J.H.; Egbert, S.L. Using USDA crop progress data for the evaluation of greenup onset date calculated from MODIS 250-meter data. Photogrammetric Engineering \& Remote Sensing 2006, 72, 1225-1234.

4. Han, K.; Champeaux, J.; Roujean, J. A land cover classification product over France at $1 \mathrm{~km}$ resolution using SPOT4/VEGETATION data. Remote Sensing of Environment 2004, 92, 52-66.

5. $\quad$ Reed, B.C.; Brown, J.F.; VanderZee, D.; Loveland, T.R.; Merchant, J.W.; Ohlen, D.O. Measuring phenological variability from satellite imagery. Journal of Vegetation Science 1994, 5, 703-714.

6. Batista, G.T.; Shimabukuro, Y.E.; Lawrence, W.T. The long-term monitoring of vegetation cover in the Amazonian region of northern Brazil using NOAA-AVHRR data. International Journal of Remote Sensing 1997, 18, 3195 - 3210.

7. Moulin, S.; Kergoat, L.; Viovy, N.; Dedieu, G. Global-scale assessment of vegetation phenology using NOAA/AVHRR satellite measurements. Journal of Climate 1997, 10, 1154-1170.

8. Schwartz, M.D.; Reed, B.C.; White, M.A. Assessing satellite-derived start-of-season measures in the conterminous USA. International Journal of Climatology 2002, 22, 1793-1805.

9. Hall-Beyer, M. Comparison of single-year and multiyear NDVI time series principal components in cold temperate biomes. Geoscience and Remote Sensing, IEEE Transactions on 2003, 41, 2568-2574.

10. Lasaponara, R. Estimating Interannual Variations in Vegetated Areas of Sardinia Island Using SPOT/VEGETATION NDVI Temporal Series. Geoscience and Remote Sensing Letters, IEEE 2006, 3, 481-483.

11. Justice, C.O.; Townshend, J.R.G.; Vermote, E.F.; Masuoka, E.; Wolfe, R.E.; Saleous, N.; Roy, D.P.; Morisette, J.T. An overview of MODIS Land data processing and product status. Remote Sensing of Environment 2002, 83, 3-15.

12. Wolfe, R.E.; Nishihama, M.; Fleig, A.J.; Kuyper, J.A.; Roy, D.P.; Storey, J.C.; Patt, F.S. Achieving sub-pixel geolocation accuracy in support of MODIS land science. Remote Sensing of Environment 2002, 83, 31-49.

13. Huete, A.; Didan, K.; Miura, T.; Rodriguez, E.P.; Gao, X.; Ferreira, L.G. Overview of the radiometric and biophysical performance of the MODIS vegetation indices. Remote Sensing of Environment 2002, 83, 195-213.

14. Huete, A.R. A soil-adjusted vegetation index (SAVI). Remote Sensing of Environment 1988, 25, 295-309. 
15. Baret, F.; Guyot, G. Potentials and limits of vegetation indices for LAI and APAR assessment. Remote Sensing of Environment 1991, 35, 161-173.

16. Gao, X.; Huete, A.R.; Ni, W.; Miura, T. Optical-Biophysical Relationships of Vegetation Spectra without Background Contamination. Remote Sensing of Environment 2000, 74, 609-620.

17. Elmore, A.J.; Mustard, J.F.; Manning, S.J.; Lobell, D.B. Quantifying Vegetation Change in Semiarid Environments: Precision and Accuracy of Spectral Mixture Analysis and the Normalized Difference Vegetation Index. Remote Sensing of Environment 2000, 73, 87-102.

18. Olson, D.M.; Dinerstein, E.; Wikramanayake, E.D.; Burgess, N.D.; Powell, G.V.N.; Underwood, E.C.; D'Amico, J.A.; Itoua, I.; Strand, H.E.; Morrison, J.C.; et al. Terrestrial Ecoregions of the World: A New Map of Life on Earth. BioScience 2001, 51, 933-938.

19. Gómez, I.A.; Gallopin, G.C. Estimacion de la productividad primaria neta de ecosistemas terrestres del mundo en relacion a factores ambientales. Ecologia Austral 1991, 1, 24-40.

20. Shimabukuro, Y.E.; Smith, J.A. The Least-Squares Mixing Models to Generate Fraction Images Derived From Remote Sensing Multispectral Data. IEEE TRANSACTIONS ON GEOSCIENCE AND REMOTE SENSING 1991, 29, 16-20.

21. Huete, A.; Justice, C.; van Leeuwen, W. MODIS Vegetation Index (MOD 13): Algorithm Theoretical Basis Document (version 3). In National Aeronautics and Space Administration: 1999; Vol. 2006, p 129.

22. Solano, R.; Didan, K.; Jacobson, A.; Huete, A. MODIS Vegetation Index (MOD 13) C5 User's Guide. In 2010.

23. Samanta, A.; Ganguly, S.; Vermote, E.; Nemani, R.R.; Myneni, R.B. Interpretation of variations in MODIS-measured greenness levels of Amazon forests during 2000 to 2009. Environmental Research Letters 2012, 7, 024018.

24. Huffman, G.J.; Bolvin, D.T.; Nelkin, E.J.; Wolff, D.B.; Adler, R.F.; Gu, G.; Hong, Y.; Bowman, K.P.; Stocker, E.F. The TRMM Multisatellite Precipitation Analysis (TMPA): Quasi-Global, Multiyear, Combined-Sensor Precipitation Estimates at Fine Scales. Journal of Hydrometeorology 2007, 8, 38-55.

25. Shimabukuro, Y.E. Shade images derived from linear mixing models of multispectral measurements of forested areas. . Colorado State University, Fort Collins, CO, 1987.

26. Kalluri, S.N.V.; Huang, C.; Mathieu-Marni, S.; Townsend, J.R.G.; Yang, K.; Chellappa, R.; Fleig, A. In A comparison of mixture modeling algorithms and their applicability to the MODIS data, Geoscience and Remote Sensing, 1997. IGARSS '97. Remote Sensing - A Scientific Vision for Sustainable Development., 1997 IEEE International, 3-8 Aug 1997, 1997; 1997; pp 171-173 vol.171.

27. Keshava, N.; Mustard, J.F. Spectral unmixing. Signal Processing Magazine, IEEE 2002, 19, 44-57.

28. Quintano, C.; Fernández-Manso, A.; Shimabukuro, Y.E.; Pereira, G. Spectral unmixing. International Journal of Remote Sensing 2012, 33, 5307-5340.

29. Roberts, D.; Keller, M.; Soares, J.V. Studies of land-cover, land-use, and biophysical properties of vegetation in the Large Scale Biosphere Atmosphere experiment in Amazônia. Remote Sensing of Environment 2003, 87, 377-388.

30. Freitas, R.M.d.; Shimabukuro, Y.E. Combining wavelets and linear spectral mixture model for MODIS satellite sensor time-series analysis. Journal of Computational Interdisciplinary Sciences 2008, 1, 51-56.

31. Souza Jr., C.; Firestone, L.; Silva, L.M.; Roberts, D. Mapping forest degradation in the Eastern Amazon from SPOT 4 through spectral mixture models. Remote Sensing of Environment 2003, 87, 494-506. 
32. Espírito-Santo, F.D.B.; Shimabukuro, Y.E.; Kuplich, T.M. Mapping forest successional stages following deforestation in Brazilian Amazonia using multitemporal Landsat images. International Journal of Remote Sensing 2005, 26, 635 642.

33. Asner; P., G.; Borghi; E., C.; Ojeda; A., R. Desertification in central Argentina: Changes in ecosystem carbon and nitrogen from imaging spectroscopy. Ecological Society of America: Washington, DC, ETATS-UNIS, 2003; Vol. 13, p 20.

34. Anderson, L.O.; Aragão, L.E.O.C.; Shimabukuro, Y.E.; Almeida, S.; Huete, A. Fraction images for monitoring intra-annual phenology of different vegetation physiognomies in Amazonia. International Journal of Remote Sensing 2011, 32, 387 408.

35. Mather, P.; Tso, B. Classification Methods for Remotely Sensed Data, Second Edition. Taylor \& Francis: 2010.

36. Townshend, J.R.G.; Huang, C.; Kalluri, S.N.V.; Defries, R.S.; Liang, S.; Yang, K. Beware of per-pixel characterization of land cover. International Journal of Remote Sensing 2000, 21, 839-843.

37. Singh, A.; Harrison, A. Standardized principal components. International Journal of Remote Sensing 1985, 6, 883 - 896.

38. Eastman, J.R.; Fulk, M. LONG SEQUENCE TIME-SERIES EVALUATION USING STANDARDIZED PRINCIPAL COMPONENTS. Photogrammetric Engineering and Remote Sensing 1993, 59, 991-996.

39. Eklundh, L.; Singh, A. A comparative analysis of standardised and unstandardised Principal Components Analysis in remote sensing. International Journal of Remote Sensing 1993, 14, 1359 - 1370.

40. Gurgel, H.C.; Ferreira, N.J. Annual and interannual variability of NDVI in Brazil and its connections with climate. International Journal of Remote Sensing 2003, 24, 3595 $-3609$.

41. Adami, M.; Freitas, R.M.d.; Padovani, C.R.; Shimabukuro, Y.E.; Moreira, M.A. Estudo da dinâmica espaço-temporal do bioma Pantanal por meio de imagens MODIS. Pesquisa Agropecuária Brasileira 2008, 43, 1371-1378.

42. IBGE, I.B.d.G.e.E. Manual técnico da vegetação brasileira. IBGE: Rio de Janeiro, 1992.

43. Perez, L.P.; Shimabukuro, Y.E.; Ferreira, N.J.; Andre, I.R.N. Dinâmica dos Principais Domínios Fitogeográficos do Nordeste Brasileiro e Suas Conexões com a Precipitação. Geografia 2004, 29, 217-228.

44. Pott, A.; Pott, V.J. Features and conservation of the Brazilian Pantanal wetland. Wetlands Ecology and Management 2004, 12, 547-552.

45. Silva, M.P.D.; Mauro, R.; Mourão, G.; Coutinho, M. Distribuição e quantificação de classes de vegetação do Pantanal através de levantamento aéreo. Revista Brasileira de Botânica 2000, 23, 143-152.

46. Baldi, G.; Guerschman, J.P.; Paruelo, J.M. Characterizing fragmentation in temperate South America grasslands. Agriculture, Ecosystems \& Environment 2006, 116, 197208.

47. Gama, J.R.V.; Souza, A.L.d.; Martins, S.V.; Souza, D.R.d. Comparação entre florestas de várzea e de terra firme do Estado do Pará. Revista Árvore 2005, 29, 607-616.

48. Alves, D.S. Space-time dynamics of deforestation in Brazilian Amazônia. International Journal of Remote Sensing 2002, 23, 2903-2908.

49. Aguiar, A.P.D.; Câmara, G.; Escada, M.I.S. Spatial statistical analysis of land-use determinants in the Brazilian Amazonia: Exploring intra-regional heterogeneity. Ecological Modelling 2007, 209, 169-188. 
50. Galford, G.L.; Mustard, J.F.; Melillo, J.; Gendrin, A.; Cerri, C.C.; Cerri, C.E.P. Wavelet analysis of MODIS time series to detect expansion and intensification of rowcrop agriculture in Brazil. Remote Sensing of Environment 2008, 112, 576-587.

51. Chacón-Moreno, E.J. Mapping savanna ecosystems of the Llanos del Orinoco using multitemporal NOAA satellite imagery. International Journal of Applied Earth Observation and Geoinformation 2004, 5, 41-53.

52. Schlegel, B.C.; Donoso, P.J. Effects of forest type and stand structure on coarse woody debris in old-growth rainforests in the Valdivian Andes, south-central Chile. Forest Ecology and Management 2008, 255, 1906-1914.

53. Ribichich, A.M. O MODELO CLÁSICO DA FITOGEOGRAFIA DA ARGENTINA: UMA ANÁLISE CRÍTICA. Interciencia 2002, 27, 669-676.

54. Villagrán, C.; Hinojosa, L. Historia de los bosques del sur de Sudamérica, II: Análisis fitogeográfico. Revista Chilena de Historia Natural 1997, 70, 241-267.

55. Herrmann, T. Indigenous Knowledge and Management of Araucaria Araucana Forest in the Chilean Andes: Implications for Native Forest Conservation. Biodiversity and Conservation 2006, 15, 647-662.

56. Hird, J.N.; McDermid, G.J. Noise reduction of NDVI time series: An empirical comparison of selected techniques. Remote Sensing of Environment 2009, 113, 248258.

57. INPE MONITORAMENTO DA COBERTURA FLORESTAL DA AMAZÔNIA POR SATÉLITES - SISTEMAS PRODES, DETER, DEGRAD E QUEIMADAS 2007-2008; INPE: São José dos Campos, 2008; p 47. 